\title{
Towards a ministry of social service and challenges of volunteerism in the church and society in Africa (Case study Nyanza Region in Kenya)
}

\author{
Prof. David H Kodia PhD \\ Great Lakes University of Kisumu Bishop Okullu College P.O. Box 7687-40100 Kisumu Kenya
}

\begin{abstract}
This article seeks to revive a debate on the role of the church in development. The main focus touches on the strategic methods that the church and society have employed in the realization of the fullness of life for their respective communities. Our specific area of research is Nyanza region of the western Kenya. There are major players in the development programs, the NGOs, the church, the government and the volunteers. The article seeks to bring into focus the core ministry of the church in a social context and to elaborate the extent at which volunteerism has been embraced at every level of development.

The article also seeks to publicize some case studies where volunteerism had been a key factor. This article is also about appreciating the role of volunteers and to go deeper to examine the impact they make in the philosophy of development. Special attention is also given to Anglican Development Services ( ADS Nyanza) which is the development wing of the Anglican Church of Kenya. The core business of the ADS is simply to translate the mission of the church in a context that is characterized with unending needs for social services. There is a lot that we learn from the challenges ADS has been facing in its endeavor which include but not limited to sound resource base, cultural attitude of the target community, and different competing interests.

The article recommends certain measures that would help the church to remain interdependent and selfsustaining.
\end{abstract}

Key words: Social ministry, meaning of volunteerism, economic empowerment, challenges, social transformation

\section{Introduction}

Social service ministry, which in other terminology is referred to as social ministry addresses the issues of common concern as they affect people's health, education, spirituality, and economic life. Social services capture the entire aspect of holistic life of a person and its community and will always be people's centered. In this article, I want to take you through very important journey that will unravel the so much talked about ministry of the church and its relevance to us today. The critical participation of the church in the life of the society is not by chance. From the very beginning, the early church had welfare programs for its needy members despite the presence of the government of the day. ${ }^{1}$

In Kisumu county of western Kenya, the church had been instrumental in addressing the issues of welfare which is characterized by elements of trials, setbacks and successes. The mundane matters of life became so much embedded in church program that some people thought that the church had abandoned its original calling of preaching the gospel. It is on this basis that I had to carry out a research on the role of the church in addressing the social concerns of the people without necessarily forsaking the pillars of its very essence.

This article is based entirely on interviews I carried with key people who are directly involved in service provision on behalf of their respective organizations. I am also going to look at other relevant themes that the local church had be struggling with to make itself relevance in the midst of competing forces. Key to this research include but not limited to Volunteerism, as new concept in service industry, the role of the church in development with specific reference to its achievements, challenges, and sustainability. The role of partners in this effort will also be discussed. Our research is centered on the Anglican Development Service.

The service provision by nongovernmental organizations has two major players: the volunteers and the full time staff.

\section{The concept of volunteerism}

When the famous American philanthropist Andrew Carnegie returned over $\$ 300$ million to society far back in 1889 , a new concept had already developed with regard to freewill sharing of resources. Motivated by

\footnotetext{
${ }^{1}$ Acts 4:23ff
} 
his own Gospel of wealth, Carnegie discovered the secret of voluntary contribution for a worthy course. But today, worthy courses are never adequately assessed. It is becoming clear that majority of our people today are suffocated by mirages and illusions which never bear desirable results. The panorama of competitive practices and expectations leaves us with no little faith left for our genuine desire for volunteerism. I am deliberately using the term genuine to explain the distinction that exist between an undertaking that is prompted by our inner desire to offer our selves and our resources for a worthy course, and that brand of undertaking that may be prompted by our own desire to participate in an activity that everyone else thinks is worthy. This second option is limited to the extent that our responses to voluntary work depend on how much pressure we are likely to receive from other external forces and the more the pressure, the greater the response.

During our research interviews with most people working either directly or indirectly with various church organizations and NGOs it came out very clearly that volunteerism is taken as the last option in an attempt to participate in development issues. Many of our respondents had different understandings of volunteerism and by extension a volunteer. The following definitions were sampled:

a) Volunteers are people who participate in development activities at no pay.

b) A volunteer is a person who is willing to offer his or her skills, time and strength towards an activity.

c) A person who gives service for free or for little pay

d) A person engaging in employment without necessarily being remunerated so as to gain skills and exposure

e) A person offering his services unconditionally

f) A volunteer is defined as an unpaid helper or assistant. Volunteerism therefore is the act of helping out at a specific task / duty / project with no pay.

However, almost every volunteer is motivated by various factors:

1. Impulsive volunteerism: Some of them are inspired by the inner feelings to use their skills for the worthy course. They get a sense of satisfaction by serving others. To them volunteerism is a sense of responsibility. This type of volunteerism is what I would prefer to call impulsive volunteerism. The volunteer is inspired to offer his services without considering the cost. The offer could be very sacrificial. These impetuous ways of responding to a duty always help in emergencies. It is to be a Good Samaritan to those who need your services.

2. Concealed Volunteerism: The other form of volunteerism is that which is prompted by the concealed desire for material gains. In this volunteerism, the volunteer is motivated by the assumption that his role in the voluntary work will be recognized and at an opportune time and he might be handsomely rewarded. The desire for these material gains is concealed. Economic driven volunteerism has its own limitations. When the expectations of the volunteer are not met within a reasonable time frame then there is a higher chance for the volunteer to fold up and exit.

3. Manipulative volunteerism: The third category of volunteerism is that which is spiced with persuasion. The volunteer is encouraged to appreciate the development work as part of his ownership. The volunteer may not have had a prior knowledge of the aims and objectives of the development project, but through persuasion he would be made to believe that the project is there for his own sake. This form of volunteerism is what I would call manipulative volunteerism. In this form of volunteerism, the volunteer is presented on the fore front as the major stake holder whereas the actual beneficiaries are concealed behind the scene.

Work without pay brings into memory the colonial policy requiring people to participate in digging trenches to control soil erosion. Even though the policy was not based on voluntary spirit and was very unpopular with the natives (Africans) it was none the less a worthy course whose pay was realized later when good crop production was realized.

According to Agnes Kola of Action Aid Kenya, Volunteerism is a noble cause that has in the recent years been abused tremendously.

There are many volunteers in this country today, most being young unemployed graduates. If assessed carefully, they lack the spirit that makes voluntarism successful but are in it to pass time, hopefully to learn something or to use it as a springboard to green pastures.

A team of educated young unemployed people come together and register a Community Based Organization (CBO). They access donor funds indicating that they are volunteers (this is the language they know will sell). Donors are attracted and 'touched' by the volunteering act. They give money for direct 
activities and not salaries or wages. The $\mathrm{CBO}$ handles big money for projects but none goes into their pockets. With time the demands in the community, their personal needs and donor reporting requirements become overwhelming and being the young ambitious educated people the group is they begin to cleverly use up the donor fund for personal needs. These personal needs many at times are basic survival needs like food and shelter

Organizations have abused volunteers. They engage interns even for several months and expect the intern to abide by their organization's rules and values at the same time taking advantage of their free labour and expertise by overworking them.

Many people have a willing spirit to help out even with no pay but practically it does not work unless personal financial needs are met.

According to Prof. Dan Kaseje the founding Director of tropical Institute for Community Health and development in Africa (TICH), volunteerism is a new concept in Africa. What we have today, is a new model patterned in the western concept. In the traditional African concept, the term volunteerism seems to be foreign. African professionals used to offer their skills and services for any worthy course. Traditional healers and herbalists were the most known experts of their time and more often than not they never charged for their services. However, the beneficiaries were free to reciprocate at their own time and within their own means. In the African context, therefore, people performed duties according to the needs and their ability without necessarily expecting negotiated benefits. Rewards for good deed may not be directly received by the volunteer, but it could be along term thing that it is the dependants of the volunteer who might be rewarded for his sake.

In the traditional African context, reciprocity for volunteer work was not clear. It is the Western model that is now coming up with a new paradigm that would enable volunteerism to enter into the world of social discipline. The Western model tends to define it and give it a clear TOR

Today volunteerism as a new social discipline, works well in the West. The reason being that in the West majority of people have the capacity to budget for their redundant time. Every time must be put in a viable use for productive gains. Majority of volunteers in the West have some other income generating engagements, and this makes it easier for them to spare some of their redundant time for voluntary services. Even though the essential nature of voluntary work sometimes is being underestimated, many organizations believe that volunteers play a pivotal role in the overall success of their organizations. There is always a contractual agreement that tends to define the primary responsibility of volunteer in an organization.

In Africa today, Volunteerism has not been adequately defined and more often than not it has been simply identified with work without pay. The ADS will at any given time engage at least five volunteers for a minimum of three months. These volunteers would do all the services in the field at no pay save for transport. The rationale for this is that the organization offers then skills they require and this translated into monetary gain is quite much. The demand for income cannot be an option and the person who works for no reward of whichever level does so for circumstances beyond his control. New economic realities bring a new trend and concept. The church choirs that practices in preparation for the Sunday service, are volunteers who are using their talents to bring life in Christian worship. However, the choir members may be family members with domestic obligations. They use their extra time for worthy course. What they need is encouragement and appreciation. Poverty context in which we operate demands new paradigms as we compete with forces of survival.

Underdevelopment in Africa widely contributes to volunteerism. In Africa almost $80 \%$ of the volunteers do not have a stable source of income and they see their participation in voluntary work as a precursor for future opportunities. And indeed, many organizations tend to recruit their best performing and professional volunteers into their pay roll.

\section{Volunteerism in the Church}

Most churches rely on volunteers in their leadership roles. In the Anglican Church for example, almost $90 \%$ of its leadership are composed of volunteers who are either elected or appointed to various key positions. In most local parishes for example, it is only the parish priest who is on a regularized employment. The rest of the leadership never get even a single cent for their work. It goes without saying that many Christians believe that they are working for the Lord and their wages may not have to be in material form. The economic situation is a major contributing factor in volunteerism. Most churches and church organizations do not have the resources to engage adequate number of human resource. This crippling scenario has by and large contributed to the spirit of volunteerism as the better option. Even though majority of volunteers would be willing to get some cash reward, it is apparent that the degrading economic circumstances do not allow this to happen. 
The Role of ADS and Social services ministry ${ }^{2}$

The main focus of ADS in development is centered on four pillars in theology and philosophy of the Anglican Church of Kenya. These are:

- Development as an act of worship, which means that good work and actions to follow humanity and creation, in order to glorify God;

- Full realization of each person's potential in life, recognizing that each person has a role and a purpose accompanied by certain responsibilities and rights;

- Stewardship of resources for sustainability and glory of God;

- Proclaiming salvation to the total person, and hence, addressing all needs- spiritual, physical, social, economic and intellectual through holistic ministry. ${ }^{3}$

In Nyanza region of western Kenya, Anglican Development Services (ADS) Nyanza is the most dominant Christian Organization. Its operation covers the whole of Nyanza province. The organization is headed by Board of directors. Board members are not paid save for their transport reimbursement and small out of pocket while on official duty. ADS is a registered company by guarantee. It has 42 staff on regular employment. But 42 staff is too small a figure compared to the vast region where the company has its operations. With the annual budget funded by donor money, it required a well managed strategy that would comfortably accommodate enough volunteers to support the staff on the ground. At the moment, the ADS has in its pool over 70 volunteers. These volunteers are members of the Zonal development Committees. Their main work is to link the community with the ADS. Since they come from the community, they understand their culture and needs much better. Apart from linkage, their role is also to market the ADS, organizing ground for their operation, and thus, act as agency for both sides. They are not paid for their services.

The role volunteer plays is very crucial for the work of the organization. The following are some of the key functions we managed to sample:

1. Mobilizing the people within their areas of operation

2. Preparing venues for meetings with the company's staff

3. Bridging the gap between the organization and the community

4. Helping to interpret the development agenda of the organization, thus creating a rapport between the organizations and the community members

5. Gathering data for analysis

The volunteers are mostly engaged for various reasons:

1. Their proximity to centers of activities give them an added advantage

2. Their act like doctors on call. They have the capacity to go extra hour.

3. They provide efficient services; many of them are professionals in their own rights.

4. According to Damaris Aketch of the catholic Archdiocese of Kisumu, volunteers have been recruited to offer medical and home based care services. Some have also written successful proposals for funding for various projects. Recently the Archdiocese launched a Microfinance scheme a project that was initiated by a certain volunteer.

5. In $\mathrm{TICH}^{4}$, many professionals have been engaged for teaching postgraduate programs and at a very low wage to cover their basic logistics. Some professionals were also engaged to oversee the design and supervision of a construction work.

6. They are cheaper in terms of financial remunerations: They do not demand salary, pension, and other financial gains. They can easily stand tough conditions even if the donor funding dries out

\footnotetext{
${ }^{2}$ ADS was originally known as Christian Community Services, ( CCS) the later changed its name to Interdiocesan Christian Community Services ( IDCCS). The development wing of the church was founded in Kenya by the late Anglican Bishop of Maseno South in mid 1990s. The idea then was to have a separate department that would address social issues affecting the people whereas the clergy would be left to address the core business of mission and evangelism. Today all Anglican dioceses have the ADS and they have a national coordinating office based in Nairobi.

${ }^{3}$ ADS Nyanza Strategic Plan 2010-2013

${ }^{4}$ TICH is Tropical Institute for Community Health and Development founded by Prof. Dan Kaseje in 1998. It was founded in the Lake City of Kismu to offer trainings for health and other professionals in the field of community health and development. Since its inception, TICH has developed and managed to found the Great lakes University of Kisumu. It still operate as one the faculties of the university. The writer had worked as its first registrar.
} 
7. They know the people at the grassroots, their weaknesses and strengths, thus giving them a fair advantage in understanding their capacity to accommodate a development proposal.

\section{The challenges of volunteerism}

The research reveals that over reliance on volunteers sometimes could have some ramification. There is a clear indication that majority of volunteers would abandon a project if they receive some offers for financial rewards. Some volunteers just disappear from the site without notice.

Majority of the volunteers may not measure up to accounting processes and should anything go wrong they are not held responsible. Again the mere fact that they are not paid, some of them find deliverable results wanting. About $87 \%$ of those interviewed expressed the wish to be employed by the organizations they serve. The volunteers also have their own problems to contend with. Since most of them may be picked by vehicles for field assignment, there is always an assumption that they are paid. This assumption has a devastating effect on relationship with others who think they could do much better. There was an organization that lost almost her entire volunteers in a certain region of operation. This happened when a more financially endowed organization promised them handouts. Even though the previous organization had trained most of them, it was not yet ready to absorb them in its employment scheme. They had the skills, but no money. The new organization counted itself lucky to have gotten trained volunteers whom they were willing to absorb even though at a lower wages.

The research also reveals that some organizations take the advantage of the volunteers' unemployed statuses. A great deal of exploitation becomes very clear when you consider the treatment accorded expatriate volunteers and those accorded the locals. The disparity is so great that the wages given the expatriates offering the same services could be compared only to an upper middle class earner.

Volunteers being unpaid stakeholders in development, they also have their own personal needs. There comes a time when personal needs override the needs of the organization. Of all the people interviewed, it was again very clear that majority of volunteers enjoy their work and would fight anyone standing on their way. They see their role in development fully satisfying. They feel that their potential has been recognized. Even though this is against the background of some misgivings especially for those who feel exploited by some organizations, the general feeling is that they cannot be ignored. However, all of them do not want to play a second fiddle.

Another discontent is about the overall participation or representation in the management. None of the organization we researched on had clear policy guidelines on volunteers. Most organizations have silently left the fate of volunteers with the management. The complain is that it is the management who needs them not the organizations. Lack of coherent policy on volunteerism has virtually watered-down the significant role played by the volunteers

\section{Recommendations}

In order for volunteerism to have a human face and be effective the following should be ensured by whoever wants to engage a volunteer:

1. That the volunteer has a steady source of income that covers their basic needs.

2. If the volunteer does not have a source of income, you should give allowances that cover for needs like accommodation and meals.

3. That the volunteer is engaged for a period of not more than three months in a row. If the volunteer is to help out in a project spanning more than three months they should be engaged as temporary employees on casual basis where they will be entitled to wages.

4. That the volunteers worth / expertise is evaluated and an enumeration given at the end of the period of volunteering.

\section{CASE STUDY 1: BWAJA VILLAGE}

Mary Amolo

Age: 58 yrs.

Organizations: Saradidi Rural Health Project and CDC

Mrs Mary Amolo has a moving story of her life experience as a volunteer. Born 48 years ago in Seme location of Kisumu District, Mary was later married in Asembo location Bwaja Village to a local counselor in 1979. Even though Mary did not reach secondary school level of education, her strong will and vague knowledge of English placed her much higher than most women married in the same village of Bwaja. Bwaja village has a population of about 4000 people. The economic life of these people is dominated by fishing business supported with some small scale farming. The village has only one primary school with a population 
of about 400 pupils. The people in this village are poor by all standards and few have had the opportunity to take their children through university education. Majority of the school going children either drop in the middle of their primary school due to pregnancy or failure to make it to secondary school due to lack of fee. Fishing business is another major stumbling block for their education since many young people get attracted to quick money from fishing.

In the late seventies and mid eighties, child mortality rate in this region was very high. Most of these cases were attributed to poor health condition, poor nutrition, malaria and other waterborne diseases. The irony was that the nearest health facility which was also poorly equipped was some $10 \mathrm{~km}$ away and sometimes inaccessible during rainy season.

It is against this background that Saradidi Rural health project was started to address health problems in Asembo specifically the regions surrounding the lake. This was the effort of Dr. Dan Kaseje the founder of the project. The aim of the health project was to reach out to the villages and identify health needs. But the project could not employ many health workers. They needed trainable people who could volunteer. The volunteers were trained in various fields:

- Community mobilization

- Midwifery

- Childcare

- Nutritional care

- Basic hygiene

Volunteers were not expected to apply. But they were selected by their own villages. They were people who were literate, trustworthy, dedicated, and strong willed. Very few fitted this description in Bwaja village, where the only celebrity available was the newly married woman from another region, Mary Amolo! This also explains the level of literacy during this time.

Mary Amolo accepted this challenge and joined her colleagues from other parts of the location for a three month course in basic health care. They also attended some weekly training in other health related areas. After the trainings, the volunteers were given the mandate to record all cases of births and deaths, help in midwifery, handling malarial drugs but always referring major cases to the health center for further actions.

\section{Challenges}

Challenges were numerous. Most villagers never accepted the fact that our tasks as volunteers were limited to identifying only needy health cases and refer them to the health center.

1.Unrealistic demands: In most cases, Mary found herself sometimes referred to as "doctor". As a "doctor", she was expected to solve all health problems. Sometimes complicated cases are reported later at night and she was expected to do something. This was the most frustrating moment, when the expectation from the villagers becomes more unrealistic. She had to be patient otherwise they are the ones who selected her for this "plum responsibility".

2. Misconception: Another challenge was due to the popular misconception that she was earning a lot of money. The mere fact that sometimes the projects land rover could be seen picking her, Mary was thought of as a woman of great influence and opportunity. She was expected to call the vehicle to pick up the sick any time a case arises. The belief that she was being paid a handsome amount of money created another problem for Mary.

The villagers appreciated her work so much, but they still believed that she could also provide them with material help. Many would come to her with genuine cases of need, like foodstuff for their babies, medicine sugar etc. It was difficult for the villagers to believe that Mary was an ordinary volunteer who was only entitled to ksh.250 as a token of appreciation.

Another challenge was suspicion. There are some who never appreciated that Mary was there for a noble course. They were suspicious that these volunteers were generally being used for some "untold reason".

3. Family responsibility: Last but not least, Mary had her family which she had to take care of. She was a wife and a mother to several children. In most cases the call of duty denied her adequate time to be with her family. The needy villagers could knock on her door even at night, thus disrupting the family fellowship. But Mary was patient and understanding 


\section{Why volunteer?}

When I asked Mary why she had to accept this frustrating responsibility she looked at me and finally gave me her words:

You see padre I was the only one from this village that was honored with this responsibility. I took it with gladness. I could not disappoint my village. This was a way of paying them back for their trust and confidence in me. Even though I am no longer working for Saradidi Rural health project, CDC has contracted us to assist in delivery cases and sampling materials to assist them with research. They pay us Ksh.440 for every delivery. They also pay us Ksh. 70 for every record of birth and death.

\section{What benefit from all these?}

Mary almost called me a capitalist when I asked the gains for all these. In deed, she admitted that the work of volunteers is hectic but cannot be measured only in terms of material gains.

"I now feel much closer to the people than when I first came to this village. There is no more joy than being accepted, trusted and appreciated. I know the whole village better than even the local chief. Every body knows me by name, and this gives me a sense of worth."

\section{Final shot:}

Mary feels somehow betrayed that when opportunity was available to engage some volunteers into full employment scheme, there was a lot of favoritism in recruitment and those who had served as volunteers for more than twenty years were not considered. However, she still enjoys working for the community. Her major regret is that the community likes taking advantage of their commitment to demand a lot. They also take time to change their behaviors.

For example, most people were forced to construct pit latrine by the provincial administration, but have declined to use them to date. Traditional beliefs inhibit awareness change. Being a volunteer is a great calling that very few people can genuinely accept. Economic realities may become a major impediment to this noble calling and it would require the organizations dealing with volunteers to do something about it.

\section{CASE STUDY 2}

\section{ACTIVATED INITIATIVES SELF HELP GROUP (ACTINA)}

The group was founded in 2002 with two primary objectives: capacity building for group members, alleviation of poverty conditions among the youth and young people in Chiga Sub location of Kisumu district. The sub location has a population of about 10,000 people with 2,500 household.

The desire to form a voluntary organization within a community setting was prompted by the desire of five of friends to found a forum where they could exercise their professional skills to help the youth and needy members of Chiga sub location. These young professionals were once college mates but were jobless. They had a strong conviction that despite being jobless they still had a vital contribution to make to the community. Chiga was identified as being one of the poorest areas within Kisumu district and its choice as a demonstration site had the recommendation of the ministry of health. The area is prone to extreme cases of flooding during rainy seasons and drought during dry season. There are usually devastating cases of diarrhea, typhoid, STIS among the youth and other waterborne diseases.

\section{Strategy:}

It was difficult for the group to realize their dreams in an environment where culture and attitude militates against so many things. The group mobilized community leaders as a way of reaching out to the others. They organized a very successful heath day during which the following cases and needs were identified:

1. lack of immunization

2. Lack of clean drinking water

3. the menace of sexually transmitted diseases mostly among the youth and the young people

4. lack of access to quality healthcare ( the sub location has only one ill equipped dispensary)

The health day provided an opportunity for baseline survey and needs assessment. Following this the group organized themselves and solicited help from well wishers. The following activities were carried out within the short time the group was founded:

a) Training for behaviour change was carried out and great impact has been noted. People are able to observe simple hygienic conditions. 
b) Water project was initiated and several shallow wells sunk courtesy of the intervention of water for Life International.

c) Community health promoters were trained to educate the people at household levels. These health promoters are trained to diagnose minor ailments, counseling, management of community pharmacy etc.

d) Youth Master trainers are also able to offer successful peer counseling

e) Newsletter was also started to help the young people in information sharing

\section{Networking:}

The group so far has had only two reliable donors. The Christian Children Fund (CCF) and the Kenya Community development Foundation helped the group with the seed money. It was the youth members themselves who initiated the link. So far the group has received help from the International Institute of Communication and development (UK) and AFRIAFIA-Kenya. Some help has also come from the Asian community (contributed drugs), Safaricom Foundation (sponsoring tournament), Aghakan Community health services (capacity building). There are several organizations that now use the youth from the group.

\section{Challenges:}

Working without pay can be stressful indeed more so when the donors decide to set standards which must be met within a given time frame. The group has every prerequisite for efficient and working organization: commitment; patience, education.

However, despite all these, they have experience numerous problems. According to the donors, they are expected not to be paid anything. Since its inception in 2002 with five founders and fifteen registered members, it is only Agnes Kola who has survived the seasons with all the frustrations notwithstanding. Many young people fell off the way after staying for several months. Due to lack of funding, it becomes apparently clear that several veterans from the group have a second thought about volunteer work. According to Agnes, helping the community is not the big deal. The big deal is how to meet the donor's expectation. She gives brief highlights of some negative experience as a volunteer for the last four years:

1. Community Pressure: The community always has the misconception that they are the donors. Even though the donors could send money specifically for activities, members of the community still believe that their cut is always there, and they will always expect handouts.

2. Donor Pressure: Most donors do not understand the community dynamics. Their demands do not always measure up to the capacity of the community. They expect the volunteers to write comprehensive report within a very short notice. Another major problem is that different donors have their own format and line of interest that sometimes conflict with that of the community. Lack of understanding of community dynamics and insensitivity to real working environment kills the spirit of many young volunteers.

3. Contemptuous behaviour: some donor representatives act contemptuously when dealing with the volunteers. Their poor PR and lack of courtesy kills the spirit of the volunteers. Volunteers do the donkey task, but the donor representative somehow deliberately fails to appreciate their contribution.

4. Temptation: The fact that the volunteers are not paid, there is always that irresistible temptation to defraud the organization. The volunteer is not capacitated well enough to enable him to stand on his own. He is expected to meet some deadlines, and the community volunteers also have their own ways of doing things.

\section{Positive experience:}

Agnes feels that her vision to assist others has been realized. She stands tall as she narrates her good side of experience. Working among the poor and needy young people was fully satisfying.. ( I had first hand experience of the agonizing touch of misery and helplessness. I am happy that I never gave up before the organization could stand and be counted as one of the most successful CBOS in the region. Through the effort of the group, others have gained tremendously. There are several girls who are on CCF sponsorship.

The voluntary work also gave many of the young and jobless professionals an opportunity to recognize their own potentials.

Unlike many other young volunteers, Agnes attributes her long stay in the group to the strong support system that she had. Her parents were working and they could take care of themselves and her other siblings; her parents in law were also well placed. This practically removed from any other extra financial burden. She could therefore stand the trials and tribulations of being a volunteer for at least longer period than her colleagues. Because of her starling record as a community worker, Agnes has now gotten a plum job with Action Aid Kenya as a program Coordinator based in Usigu area in Bondo District. 


\section{ADS challenges and successes}

For many years ADS had been the main wing of the church in the development and the social transformation it has made in the region cannot be underestimated. It has been involved in water project, sinking shallow wells for the local community, buying water tank for local institutions and the most vulnerable and encouraging use of rain water catchment for domestic use. It has been involved also in agriculture, preventive and promotive health services, economic empowerment with value addition, and financial management. ADS Nyanza is believed to be the biggest church development agency in the region with an annual budget of Ksh. 30 million.

Success stories

There are two major success stories attributed to ADS work in the region. The first is economic empowerment program. This project targeted a community of farmers in Kabondo-Nyapalo. The community is traditionally sweet potatoes growers. However, despite the community's excellence in sweet potatoes farming, the middle men scam became a major handicap in their effort to reap maximum benefit for their work. The middle men would come and purchase their produce at the lowest price based on their own terms. It was an open exploitation that the ADS intervention was seen as a milestone in the commercialization of their farming. The ADS moved in and helped them through sensitization seminars to form cooperative movement that would buy and market for them their produce. The county government of Kisumu also gave them land where they constructed their center. All the potatoes grown and meant for sale are brought at the center where they are weighed and prices determined by the market rather than negotiation. Through the assistance of one of the mobile service providers, the corporative members were also taken through ICT training and software was fitted in their mobiles which they can use to monitor the market situation for their produce.

It is not just the sale of the sweet potatoes that was crucial in this initiative. The ADS also introduced the aspect of value addition. They introduced a popular project of drying the sweet potatoes and use its flour for baking cakes and bread for local consumption.

The initiative has also witnessed the widening of the market for sweet potatoes evidenced by the opening of a market in the UK as well. A new concept of planned harvesting through staggering of planting was also introduced to allow for a continuous production.

The second success story is based on agricultural sector in Siaya County. There is a community in Ugenya Siaya that had been growing ground nuts in a small scale for domestic consumption. However, due to economic hardship, many farmers started to abandon the farming because of its low return. It was at this point that the ADS came in to give them trainings on economic empowerment including value addition principles. Through this initiative, the farmers are now able to grow more groundnuts not only for domestic consumption but also for making branded peanut butter for the local and neighboring markets. The Eastcom butter is found in some super markets in Busia town and the neighboring Uganda.

\section{Challenges}

Behind every success there are major challenges. ADS Nyanza has faced numerous challenges. One major challenge is about finance. It is a great pity that since its operation more than three decades ago, ADS is still $100 \%$ donor funded. Even though the local input cannot be ignored, like offering free office space for the staff, it is an obvious fact that should the donors pull out, that would be the eventual end of ADS activities. The issue of funding is critical for any social ministry to be relevant. It is on this basis that sustainability is now becoming the main agenda within the ADS circles. What is it that the ADS and other local NGOs can do to remain relevant even in the unlikely event that the donors pull out. The problems associated with donor funding are numerous too. Donors have their own priorities which may not necessarily reflective of the needs of the local community. Changes in their policies and strategies sometimes get the local partners off guard. There are some proposals to create subsidiary agencies whose mandate would be to make business for profit on behalf of the local organizations. The Anglican Church just like many other mainline churches has established companies that manage business on its behalf. In this way, the church remains with its core business of preaching the gospel whereas the companies generate resources to support its social ministry programs.

The third challenge is HIV/AIDS ${ }^{5}$ pandemic. Nyanza region according to government statistics is ranked one of the top regions with high rate of HIV prevalence. Most young people have succumbed to the scourge whereas the older generations have exhausted their energy for heavy duties.

\footnotetext{
${ }^{5}$ The availability of free ARV has helped to reduce this figure
} 
The fourth challenge is based on cultural attitude towards work. Many people in this region like lazing about and always enjoy talking politics at the expense of development. It is difficult for them to change their attitude towards new ideas. Through prolonged education and social interaction they would pick up. There are also some people who are still stuck in their traditional beliefs and it becomes very difficult to help them.

Last but not least, there is a conflict of interest fronted by other players in the field. There are some well moneyed NGOs that prefer giving out handouts. This has destabilized the region a bit as many people would rather identify with NGOs that give money than mere teachings. People become less serious with their own initiatives the very moment they know that they will be paid. However, these handouts have not helped to redress the sorry situation. It is like giving a person a fish and refuse to train him on how to be independent by knowing to fish.

\section{Conclusion}

Social service is an open ended opportunity for every responsible citizen to engage in a productive activity for the common good. My main concern is that most communities do not consider the elements of human factor that would require us to appreciate every service offered to us ex-gratia. Numerous efforts to counter the imminent struggle for survival may warrant a new approach, comprehensive enough to address the gaps that exist in our potentials to remain whole, relevant and productive. Whenever we are faced with certain dilemmas of great proportion, our consciousness to recognize the presence of a third party with a helping hand equally remains unavoidable. It is for this reason that we have to salute every person whose contribution gives our life some meaning. Socialist approach to empowering the needy in our midst may not be all that necessary so long us we allow our strategic objectives to be dictated by both human factor as well as our philosophy of good practice. Forces of transformation should organize mechanisms that would compel the national governments to address key issues affecting the citizens and how best volunteers should be appreciated both in kind and cash for the services they render. Unless this is done, volunteerism would acquire a status of exploitations. 